\title{
USO DE EFLUENTES DA CARCINICULTURA DE ÁGUAS INTERIORES NA IRRIGAÇÃO DO ARROZ
}

\section{USE OF INLAND SHRIMP FARM EFFLUENT FOR RICE IRRIGATION}

\author{
FÁBIO RODRIGUES DE MIRANDA \\ Pesquisador A da Embrapa Agroindústria Tropical. PhD em Engenharia de Biossistemas pela The University \\ of Tennessee, Estados Unidos \\ FRANCISCO EDSON A. SOUZA JR. \\ Engenheiro Civil, Engesoft Engenharia e Consultoria Ltda
}

RAIMUNDO N. LIMA

Pesquisador B de Embrapa Agroindústria Tropical. Mestre em Fitotecnia pela UFC

CARMEM C. M. SOUSA

Bolsista da Embrapa Agroindústria Tropical. Engenheira Agrônoma pela UFC

MARIA G. S. SANTANA

Bolsista da Embrapa Agroindústria Tropical. Estudante de Agronomia pela UFC

Carlos A. G. Costa

Bolsista da Embrapa Agroindústria Tropical. Engenheiro Agrônomo pela UFC

Recebido: 09/04/08 Aceito: 10/07/08

\section{RESUMO}

O trabalho objetivou avaliar a produção de arroz e as alterações químicas do solo, em resposta à irrigação com o efluente da carcinicultura de águas interiores e comparar os resultados com aqueles obtidos com a irrigação convencional, utilizando água do Rio Jaguaribe. A produção de grãos obtida com o uso do efluente da carcinicultura foi semelhante àquela obtida com o uso da água de rio, quando foi utilizada na adubação uma dose de N-P-K equivalente a $100 \%$ da dose recomendada para a cultura. $\mathrm{O}$ uso do efluente na irrigação proporcionou maior produção de grãos em relação à irrigação com a água de rio, quando foi utilizada uma dose de N-P-K equivalente a 75\% daquela recomendada para a cultura do arroz. Após o cultivo, o solo irrigado com o efluente apresentou maiores níveis de $\mathrm{Na}^{+}, \mathrm{CE}_{\text {es }}$ e PST em relação ao solo irrigado com a água do Rio Jaguaribe.

PALAVRAS-CHAVE: L. Vannamei, Oryza sativa L., salinização do solo, carcinicultura, reúso de águas.

\section{ABSTRACT}

This study aimed to evaluate rice yield and soil chemical alterations in response to inland shrimp farm effluent use for irrigation, comparing the results to conventional irrigation, using the Jaguaribe River water. Rice yield obtained with the effluent was similar to that obtained with river water irrigation, when the $N-P-K$ dose applied was equivalent to $100 \%$ of the crop recommended dose. Effluent irrigation produced higher grain yield as compared to river water irrigation when the $N-P$-K dose applied was equivalent to $75 \%$ of the rice recommended dose. After the crop was harvested the soil irrigated with the effluent presented higher levels of $\mathrm{Na}^{+}, E C$ and ESR, as compared to the soil irrigated with the Jaguaribe River water.

KEYWORDS: L. Vannamei, Oryza sativa L., soil salinization, shrimp farming, water reuse.

\section{INTRODUÇÃO}

A adaptação da espécie L. vannamei a águas com baixa salinidade vem contribuindo para o crescimento da atividade de carcinicultura também em águas interiores. $\mathrm{Na}$ região do Baixo Jaguaribe-CE observa-se a instalação progressiva de fazendas de camarão às margens do Rio Jaguaribe onde não há interferência de água salina. Os efluentes gerados nessas fazendas, que em 2004 compreendiam uma área total de 413 ha, são lançados nos corpos d'água da bacia sem tratamento prévio, sendo o Rio Jaguaribe o principal receptor (Figueiredo et al, 2005).

Dentre as principais questões ambientais relacionadas à carcinicultura em águas interiores, destacam-se o elevado consumo de água e a contaminação dos corpos hídricos por efluentes não tratados. Os efluentes da carcinicultura freqüentemente apresentam níveis mais elevados de alguns nutrientes, plâncton, sólidos suspensos e demanda de oxigênio que os corpos hídricos receptores (Boyd, 2003). Consequentemente, esses efluentes são considerados fontes potenciais de poluição, contribuindo 
para a eutrofização de rios e lagoas onde são lançados (Dierberg \& Kiattisimkul, 1996; Paez-Osuna et al,1998).

Figueiredo et al (2005) recomendaram o tratamento prévio dos efluentes da carcinicultura de baixa salinidade antes de serem lançados nos corpos hídricos, através do uso de bacias de sedimentação, da recirculação e do uso dos efluentes nas próprias fazendas. Entre as alternativas de uso, a irrigação de cultivos é apontada como uma das mais viáveis.

A integração da aqüicultura com a agricultura pode ser uma solução para alcançar um uso mais eficiente dos recursos hídricos, maximizando a produção da propriedade rural, sem aumentar o seu consumo de água. Além disso, a utilização de efluentes ricos em nutrientes na irrigação de cultivos pode permitir a redução do uso de fertilizantes (McIntosh \& Fitzsimmons, 2003).

Entre as culturas mais plantadas na região do Baixo Jaguaribe, destaca-se a cultura do arroz, em virtude da experiência dos produtores e da existência de solos com boas características para o seu cultivo sob irrigação por superfície. $\mathrm{O}$ presente estudo teve como objetivos avaliar a produção de arroz e as alteraçóes químicas do solo, em resposta à irrigação com o efluente da carcinicultura de águas interiores e comparar os resultados com aqueles obtidos com a irrigação utilizando a água de rio.

\section{METODOLOGIA}

O experimento foi conduzido no período de julho a novembro de 2005 , na Fazenda Poço de Onça, localizada no município de Russas, CE. O solo do local é do tipo NEOSSOLO FLÚVICO, textura franco, com teores de areia, silte e argila de 460, 360 e $180 \mathrm{~g} . \mathrm{kg}^{-1}$, respectivamente. A velocidade de infiltração básica do solo (VIB) foi determinada in situ utilizando o método do infiltrômetro de anel, observando-se um valor médio de VIB de $2,81 \mathrm{~mm} \cdot \mathrm{h}^{-1}$. A fazenda utiliza água do Rio Jaguaribe para a criação de camarão da espécie L. vannamei, em dois viveiros com área de três hectares cada.

Utilizou-se o delineamento experimental de blocos casualizados, em um esquema fatorial $2 \times 2$, com cinco repetições. Os tratamentos utilizados foram:

E100 - Irrigação com o efluente e aplicação de $100 \%$ da dose de N-P-K recomendada para a cultura do arroz;

E75 - Irrigação com o efluente e aplicação de $75 \%$ da dose de N-P-K recomendada para a cultura do arroz;

R100 - Irrigação com água do Rio Jaguaribe e aplicação de $100 \%$ da dose de N-P-K recomendada para a cultura do arroz;

R75 - Irrigação com água do Rio Jaguaribe e aplicação de $75 \%$ da dose de N-P-K recomendada para a cultura do arroz;

A área experimental de $2.000 \mathrm{~m}^{2}$ foi sistematizada e dividida em 20 tabuleiros de irrigação por inundação, com dimensôes de 10 × $10 \mathrm{~m}$, que constituíram as parcelas (Figura 1). A fim de evitar o fluxo lateral de água através das paredes dos tabuleiros, foi instalada entre eles uma manta de polietileno, da superfície do solo até uma profundidade de $1 \mathrm{~m}$.

O fornecimento de água nas parcelas foi realizado utilizando-se dois sistemas de irrigação, um para cada tipo de água, constituídos, cada um, por uma bomba centrífuga, tubulação de PVC e uma válvula de descarga em cada parcela. Em cada sistema foi instalado um hidrômetro para o monitoramento do volume de água aplicado nas irrigações. No caso do efluente, o bombeamento foi realizado do canal de descarga onde são lançados os efluentes contínuos e da despesca dos viveiros de camarão.

Com base na análise de fertilidade do solo foram definidas as doses de $\mathrm{N}-\mathrm{P}-\mathrm{K}$ requeridas pela cultura do arroz, de acordo com Raij et al (1997). Nos tratamentos com $100 \%$ da adubação recomendada para o arroz, foram aplicados antes do plantio $200 \mathrm{~kg} \cdot \mathrm{ha}^{-1} \mathrm{da}$ formulação N-P-K 15-15-15, o que representou a aplicação de 30, 30 e $30 \mathrm{~kg} \cdot \mathrm{ha}^{-1}$ de $\mathrm{N}, \mathrm{P}_{2} \mathrm{O}_{5}$ e $\mathrm{K}_{2} \mathrm{O}$, respectivamente. Nos tratamentos com $75 \%$ da adubação recomendada para o arroz foram aplicados antes do plantio $150 \mathrm{~kg} \cdot \mathrm{ha}^{-1}$ da formulação N-P-K 15-15-15, o que representou a aplicação de 22,5; 22,5 e 22,5 kg.ha-1 de $\mathrm{N}, \mathrm{P}_{2} \mathrm{O}_{5}$ e $\mathrm{K}_{2} \mathrm{O}$, respectivamente. A distribuiçấo dos fertilizantes foi feita a lanço, seguida de incorporação com cultivador de tração animal, na profundidade de 0,05 m.

No plantio utilizou-se a variedade de arroz IRGA 417, plantada no espaçamento de $0,30 \mathrm{~m}$ entre sulcos, com 100 sementes por metro linear. A contagem do estande foi realizada 30 dias após o plantio e apresentou um número médio de 330 plantas $\mathrm{m}^{-2}$.

Logo após o plantio foi aplicada uma lâmina de irrigação de $150 \mathrm{~mm}$ de água. Após a germinação, até a cultura alcançar uma cobertura do solo de $80 \%$, as irrigações foram realizadas diariamente, procurando-se manter uma lâmina de água nos tabuleiros de altura variável, de acordo com o crescimento das plantas. A partir de $80 \%$ de cobertura do solo as irrigações foram realizadas a cada três dias, aplicandose uma lâmina média de $50 \mathrm{~mm}$ por irrigação.

Amostras da água do Rio Jaguaribe e do efluente utilizados na irrigação

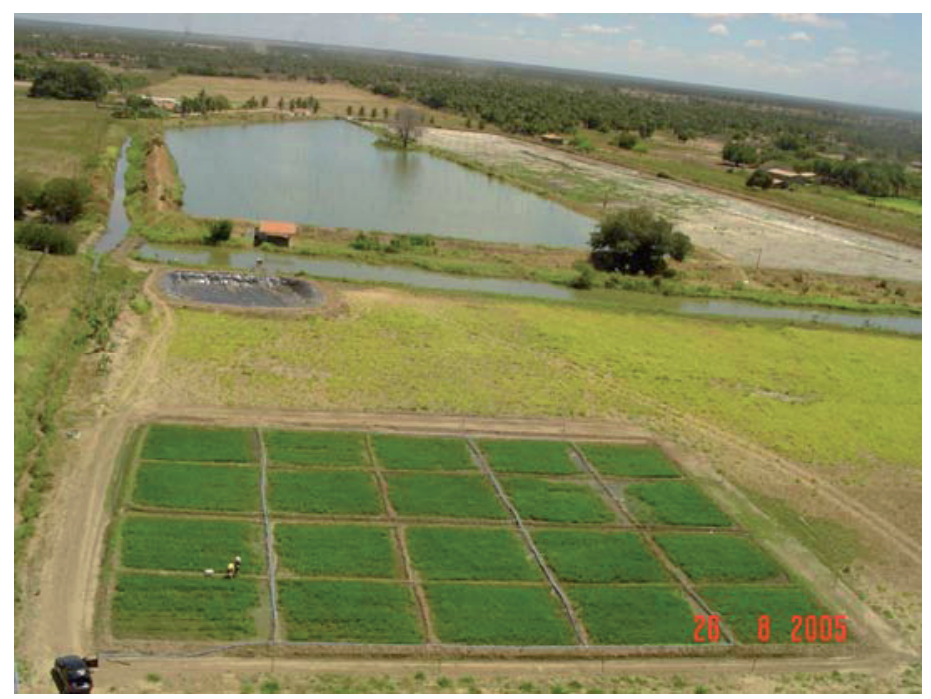

Figura I- Vista da área experimental aos 48 dias após o plantio do arroz, vendo-se ao fundo os viveiros de camarão e o canal de descarga dos efluentes 
foram coletadas a cada 15 dias e analisadas no Laboratório de Solo e Água da Embrapa Agroindústria Tropical. As amostras foram analisadas quanto ao $\mathrm{pH}, \mathrm{CE}_{\mathrm{a}}, \mathrm{RAS}$ e as concentraçóes de $\mathrm{N}$ - Amoniacal, Nitrato, N - Total, P, $\mathrm{K}^{+}$, $\mathrm{Ca}^{2+}, \mathrm{Mg}^{2+}$ e $\mathrm{Na}^{+}, \mathrm{Cl}^{-}, \mathrm{SO}_{4}^{2-}, \mathrm{CO}_{3}{ }^{2-} \mathrm{e}$ $\mathrm{HCO}_{3}^{-}$, conforme Silva (1999).

As adubaçôes de cobertura foram realizadas a lanço, aos 18, 34 e 46 dias após o plantio. Foram aplicadas doses de 115 e 86 kg.ha- ${ }^{-1}$ de N, para os tratamentos com 100 e $75 \%$ da adubação recomendada para o arroz, respectivamente, na forma de uréia ( $44 \%$ de $\mathrm{N}$ ). $\mathrm{O}$ controle de plantas daninhas foi realizado com a aplicação dos herbicidas 2,4-D e Propanil 360, aos 16 dias após o plantio, na dosagem de 0,25 e 1,80 L.ha-1 ${ }^{-1}$ respectivamente.

A colheita foi realizada aos 108 dias após o plantio, quando mais de 90\% das panículas apresentavam coloração típica de grãos fisiologicamente maduros. Em cada parcela foram colhidas as plantas de três áreas amostrais de $6 \mathrm{~m}^{2}(3,0 \times 2,0 \mathrm{~m})$. As amostras foram acondicionadas em caixas de papelão e deixadas ao sol para secagem por sete dias, após o que foram debulhadas manualmente. A seguir foram determinadas em cada amostra a produção de grãos em casca, a massa de 100 grãos e o peso hectolítrico. $\mathrm{O}$ teor de umidade dos grãos de cada amostra foi determinado pelo método de secagem em estufa por 24 horas a $105^{\circ} \mathrm{C}$. Os dados de produção, peso hectolítrico e massa de 100 grãos foram então corrigidos para a umidade de $13 \%$ e submetidos à análise de variância.

Para a análise das alterações dos atributos químicos do solo foram coletadas amostras de solo antes do plantio (tempo 0) e após a colheita do arroz (tempo 1), nas profundidades de 0 a 0,$2 ; 0,2$ a 0,4 e 0,4 a $0,6 \mathrm{~m}$, em todas as parcelas. $\mathrm{Na}$ análise estatística dos atributos do solo realizou-se uma análise descritiva utilizando comparação de médias e o teste de $\mathrm{t}$ para verificar a significância estatística.

\section{RESULTADOS}

\section{Água de irrigação}

$\mathrm{Na}$ Tabela 1 são apresentados os valores médios de algumas características químicas do efluente e da água do Rio Jaguaribe observados durante o experimento. Praticamente não houve diferença entre o efluente e a água do rio com relação aos níveis de $\mathrm{pH}, \mathrm{Ca}^{2+}$, $\mathrm{Mg}^{2+}, \mathrm{K}^{+}, \mathrm{Na}^{+}, \mathrm{Cl}^{-}, \mathrm{HCO}_{3}^{-}$, e RAS. O efluente apresentou valores médios de $\mathrm{CE}_{\mathrm{a}}, \mathrm{P}, \mathrm{SO}_{4}^{2-}, \mathrm{N}$-amoniacal, N-nitrato e N-total maiores que a água do rio. No entanto, em virtude da variação dos parâmetros analisados ao longo do experimento, foi observada diferença significativa $(\mathrm{p}<0,05)$ apenas em relação à $\mathrm{CE}_{\mathrm{a}}$.

De acordo com as diretrizes apresentadas por Ayers \& Westcot (1999), tanto a água do rio, quanto o efluente apresentariam um grau de restrição ligeiro a moderado para uso na irrigação, quando considerados os valores de $\mathrm{CE}_{2}$ e RAS e o teor de $\mathrm{Na}^{+}$.

\section{Produção de arroz}

A maior produção de grãos entre os tratamentos estudados foi obtida com a utilização do efluente na irrigação do arroz e a aplicação de $75 \%$ da dose de N-P-K. A produção de grãos do tratamento E75 foi significativamente superior $(\mathrm{p}<0,05)$ à do tratamento com a água do rio e $75 \%$ da dose de N-P-K e semelhante às produçôes obtidas com ambos os tipos de água e $100 \%$ da dose de N-P-K (Tabela 2).

Não houve diferença significativa entre os tratamentos quanto ao peso hectolítrico do arroz. Quanto à massa de 100 grãos, verificou-se que o tratamento com a água do rio e $100 \%$ da adubação apresentou uma média significativamente superior aos demais tratamentos.

A análise de variância mostrou que houve um efeito significativo $(\mathrm{p}<0,05)$

Tabela I - Características químicas médias do efluente da carcinicultura e da água do Rio Jaguaribe utilizados no experimento

\begin{tabular}{|c|c|c|c|c|c|}
\hline \multirow[t]{2}{*}{ Parâmetro } & \multicolumn{2}{|c|}{ Efluente } & \multicolumn{2}{|c|}{ Rio } & \multirow{2}{*}{$\begin{array}{c}\text { Diferença } \\
(\mathrm{E}-\mathrm{R})\end{array}$} \\
\hline & Média & Desvio padrão & Média & Desvio padrão & \\
\hline $\mathrm{pH}$ & 8,26 & 0,62 & 8,46 & 0,17 & $-0,20$ ns \\
\hline $\mathrm{P}\left(\mathrm{mg} \mathrm{L}^{-1}\right)$ & 0,20 & 0,12 & 0,06 & 0,03 & $0,14^{\mathrm{ns}}$ \\
\hline $\mathrm{Ca}^{2+}\left(\mathrm{mg} \mathrm{L}^{-1}\right)$ & 27,29 & 8,02 & 27,94 & 4,02 & $-0,65$ ns \\
\hline $\mathrm{Mg}^{2+}\left(\mathrm{mg} \mathrm{L}^{-1}\right)$ & 22,40 & 8,47 & 23,93 & 9,99 & $-1,53^{\mathrm{ns}}$ \\
\hline $\mathrm{K}^{+}\left(\mathrm{mg} \mathrm{L}^{-1}\right)$ & 8,53 & 2,60 & 7,91 & 1,97 & $0,62^{\text {ns }}$ \\
\hline $\mathrm{Na}^{+}\left(\mathrm{mg} \mathrm{L}^{-1}\right)$ & 103,95 & 9,14 & 96,23 & 12,44 & $7,72^{\mathrm{ns}}$ \\
\hline $\mathrm{Cl}^{-}(\mathrm{mg} \mathrm{L}-1)$ & 164,82 & 30,25 & 149,10 & 28,99 & $15,72^{\mathrm{ns}}$ \\
\hline $\mathrm{SO}_{4}^{2-}\left(\mathrm{mg} \mathrm{L}^{-1}\right)$ & 15,50 & 10,22 & 7,95 & 4,67 & $7,54^{\mathrm{ns}}$ \\
\hline $\mathrm{CO}_{3}^{2-}\left(\mathrm{mg} \mathrm{L}^{-1}\right)$ & 4,33 & 2,80 & 10,63 & 6,15 & $-6,30^{\mathrm{ns}}$ \\
\hline $\mathrm{HCO}_{3}^{-}\left(\mathrm{mg} \mathrm{L}^{-1}\right)$ & 157,38 & 26,49 & 163,22 & 17,12 & $-5,84^{\mathrm{ns}}$ \\
\hline N Amoniacal $\left(\mathrm{mg} \mathrm{L}^{-1}\right)$ & 0,56 & 0,50 & 0,24 & 0,18 & $0,32^{\mathrm{ns}}$ \\
\hline N Nitrato $\left(\mathrm{mg} \mathrm{L}^{-1}\right)$ & 0,84 & 0,67 & 0,30 & 0,23 & $0,54^{\mathrm{ns}}$ \\
\hline N Total $\left(\mathrm{mg} \mathrm{L}^{-1}\right)$ & 6,30 & 4,54 & 2,89 & 1,63 & $3,41^{\mathrm{ns}}$ \\
\hline $\mathrm{CE}_{\mathrm{a}}\left(\mathrm{dS} \mathrm{m}^{-1}\right)$ & 0,77 & 0,07 & 0,68 & 0,06 & $0,09 *$ \\
\hline RAS & 3,63 & 0,56 & 3,27 & 0,34 & $0,36^{\mathrm{ns}}$ \\
\hline
\end{tabular}

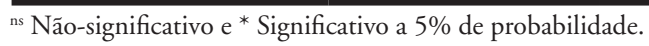


da interação entre o tipo de água utilizado na irrigação e as doses de N-P-K para as variáveis produção e massa de 100 grãos. O desdobramento da interação água $\mathrm{x}$ adubação para a variável produção de grãos mostrou que não houve diferença entre os tratamentos de irrigação quando foram aplicados 100\% da adubação recomendada para o arroz (Tabela 3). No entanto, quando foram aplicados apenas $75 \%$ da adubação recomendada para a cultura, a produção obtida com a utilização do efluente foi significativamente superior $(p<0,05)$ em relação à produção obtida com a água do rio.

Para a variável massa de 100 grãos constatou-se que o tratamento com efluente foi significativamente superior $(\mathrm{p}<0,05)$ ao tratamento com a água do rio, quando utilizou-se $75 \%$ da dose de N-P-K recomendada para o arroz (Tabela 4). No entanto, o tratamento com a água do rio foi superior ao tratamento com o efluente, quando utilizou-se $100 \%$ da dose de N-P-K recomendada.

\section{Características químicas do solo}

Antes do cultivo não existiam diferenças significativas entre os tratamentos para as características químicas do solo avaliadas (Tabela 5). Após o cultivo do arroz, o solo irrigado com o efluente passou a ter níveis significativamente mais elevados de $\mathrm{CE}_{\text {es }}$ na camada de 0 a $0,60 \mathrm{~m}$ e de $\mathrm{Na}^{+}$e PST na profundidade de 0 a 0,20 m, em relação ao solo irrigado com a água de rio.

Com relação à salinidade, de acordo com a classificação apresentada por Pizarro (1978), antes do cultivo o solo era classificado como normal e com praticamente nenhum efeito prejudicial da salinidade sobre o rendimento das culturas, em virtude de apresentar PST $<7 \%$ e $\mathrm{CE}_{\mathrm{es}}<2 \mathrm{dS} \mathrm{m}^{-1}$. No entanto, houve um aumento expressivo do PST durante o cultivo em ambos os tratamentos, o que fez com que o solo passasse a ser classificado como ligeiramente sódico $(7<\mathrm{PST}<15)$ na camada de 0 a $0,60 \mathrm{~m}$ de profundidade.

$\mathrm{Na}$ Tabela 6 são apresentadas as alterações ocorridas em algumas características químicas do solo em decorrência do cultivo do arroz, utilizando o efluente da carcinicultura de águas interiores e a água do Rio Jaguaribe na irrigação. A maior parte das alterações

Tabela 2 - Valores médios de produção de grãos de arroz em casca, peso hectolítrico e massa de 100 grãos em resposta à irrigação com efluente da carcinicultura e água do rio Jaguaribe, utilizando-se $100 \%$ e 75\% da dose de N-P-K recomendada para a cultura

\begin{tabular}{|c|c|c|c|}
\hline Tratamento & $\begin{array}{l}\text { Produção de grãos } \\
\left(\mathrm{kg} \cdot \mathrm{ha}^{-1}\right)\end{array}$ & $\begin{array}{c}\text { Peso hectolítrico } \\
(\mathrm{kg})\end{array}$ & $\begin{array}{c}\text { Massa de } 100 \text { grãos } \\
(\mathrm{g})\end{array}$ \\
\hline R100 & $6293,30 \mathrm{ab}$ & $59,67 \mathrm{a}$ & $2,57 \mathrm{a}$ \\
\hline R75 & $5795,40 \mathrm{~b}$ & $58,22 \mathrm{~A}$ & $2,44 \mathrm{~b}$ \\
\hline E100 & $6161,60 \mathrm{ab}$ & $58,34 \mathrm{a}$ & $2,48 \mathrm{~b}$ \\
\hline E75 & $6520,60 \mathrm{a}$ & $58,16 \mathrm{a}$ & $2,48 \mathrm{~b}$ \\
\hline
\end{tabular}

Teste F

$\begin{array}{clcr}\text { Irrigação (I) } & 2,82^{\mathrm{ns}} & 1,35^{\mathrm{ns}} & 1,60^{\mathrm{ns}} \\ \text { Adubação (A) } & 0,15^{\mathrm{ns}} & 1,86^{\mathrm{ns}} & 11,85^{*} \\ \text { I x A } & 5,88^{*} & 1,13^{\mathrm{ns}} & 13,83^{*} \\ \text { C.V. }(\%) & 11,05 & 3,95 & 2,92\end{array}$

(1) Médias seguidas pela mesma letra dentro de cada coluna não diferem entre si pelo teste de Tukey a $5 \%$ de probabilidade.

(2) ns Não-significativo e * Significativo a $5 \%$ de probabilidade.

Tabela 3 - Produção de grãos em resposta à irrigação com efluente da carcinicultura e água de rio, aplicando-se 75\% e 100\% da dose de N-P-K recomendada para a cultura do arroz

Tipo de água Produção de grãos $\left(\mathrm{kg} \cdot \mathrm{ha}^{-1}\right)$

Dose de N-P-K 75\% Dose de N-P-K 100\%

$\begin{array}{cll}\text { Efluente } & 6520,60 \mathrm{a} & 6161,60 \mathrm{a} \\ \text { Rio } & 5795,40 \mathrm{~b} & 6293,30 \mathrm{a}\end{array}$

Médias seguidas pela mesma letra dentro de cada coluna não diferem entre si pelo teste de Tukey a $5 \%$ de probabilidade.

Tabela 4 - Valores médios da massa de 100 grãos de arroz em resposta à irrigação com a água do rio Jaguaribe e com efluente da carcinicultura, aplicando-se 75\% e $100 \%$ da dose de N-P-K recomendada para a cultura

\begin{tabular}{ccc}
\hline Tipo de água & \multicolumn{2}{c}{ Massa de 100 grãos $(\mathrm{g})$} \\
& Adubação $75 \%$ & Adubação $100 \%$ \\
\hline Efluente & $2.48 \mathrm{a}$ & $2.48 \mathrm{~b}$ \\
Rio & $2.44 \mathrm{~b}$ & $2.57 \mathrm{a}$ \\
\hline
\end{tabular}

Médias seguidas pela mesma letra dentro de cada coluna não diferem entre si pelo teste de Tukey a $5 \%$ de probabilidade.

significativas dos atributos químicos do solo ocorreu na profundidade de 0 a $0,2 \mathrm{~m}$. P e $\mathrm{K}^{+}$aumentaram significativamente ao longo do ciclo de cultivo, tanto com o efluente, quanto com a água do rio. Esses aumentos de $\mathrm{P}$ e $\mathrm{K}^{+}$ provavelmente foram decorrentes $\mathrm{da}$ fertilização química da cultura.

Houve um aumento significativo do $\mathrm{pH}$ na camada de 0 a $0,2 \mathrm{~m}$ apenas quando o solo foi irrigado com a água do rio. $\mathrm{Ca}^{2+}$ e $\mathrm{Mg}^{2+}$ diminuíram significativamente $(\mathrm{P}<0,01)$ na camada de
0 a $0,2 \mathrm{~m}$ no tratamento com a água do Rio. No entanto, não houve variação significativa dos níveis de $\mathrm{Ca}^{2+}{\mathrm{e} \mathrm{Mg}^{2+}}^{2+}$ em nenhuma das camadas estudadas com a utilização do efluente.

$\mathrm{O} \mathrm{Na}{ }^{+}$e a PST aumentaram significativamente em todas as profundidades do solo, para os dois tipos de água utilizados na irrigação. $\mathrm{O}$ uso do efluente na irrigação causou aumentos significativos $(P<0,01)$ da $\mathrm{CE}_{\text {e }}$ nas camadas de 0 a 0,2 e 0,4 a $0,6 \mathrm{~m}$. No solo irrigado com a água do rio foi observado um aumento significativo 
(ै)

되

घ

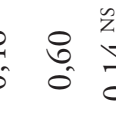

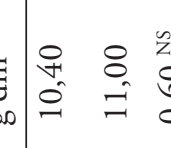

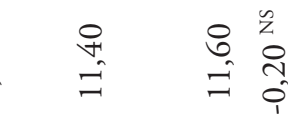

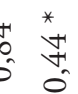

$\begin{array}{lll}0 & & n \\ n & n & z \\ 0 & 0 & 0 \\ 0 & 0\end{array}$

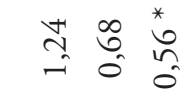

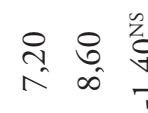

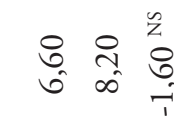

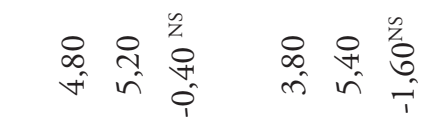

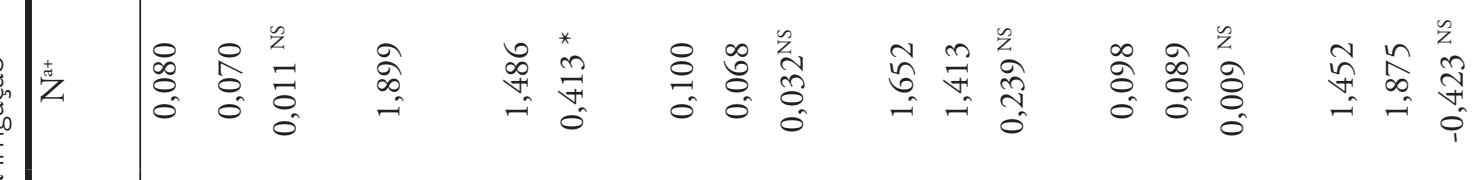

$\circ \stackrel{0}{\frac{\pi}{2}}$

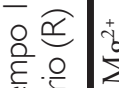

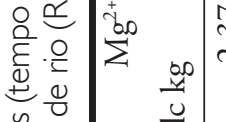

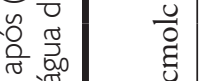

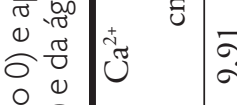

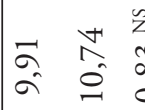

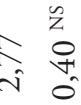

$\begin{array}{lll}a & z & z \\ i & i & 0\end{array}$

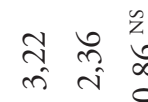

$\begin{array}{llll}n & n & n & z \\ 0 & i & 0 & 0 \\ 0 & i & i & 0\end{array}$

S.

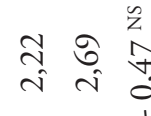

$\begin{array}{lll}n & n \\ \hat{0} & 0 & 0 \\ i & 0 & 0 \\ i & 0 & 0\end{array}$

$\sum_{\infty}^{\infty}$

$\begin{array}{ccc}n & n \\ n & n & n \\ n & n & n\end{array}$

$\begin{array}{ll}\stackrel{0}{z} \\ \stackrel{+}{*} \\ = & 0 \\ = & 0 \\ = & 0\end{array}$

$\begin{array}{lll}8 & 0 & z \\ 0 & \infty & 0 \\ 0 & 0 & 0\end{array}$

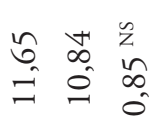

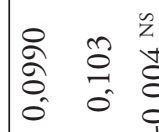

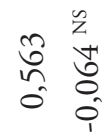

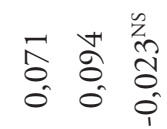



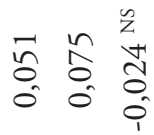

$\begin{array}{cc} & n \\ 0 & z \\ +12 & 0 \\ 00 & 0\end{array}$

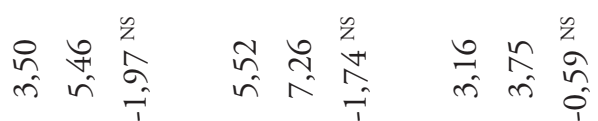

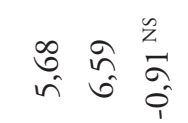

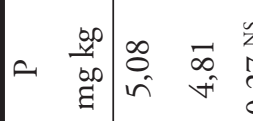

$\hat{0}$
$\infty$

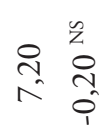

$\begin{array}{lll}\infty & \infty & n \\ 2 & \infty & z \\ \sigma & 0 & 0 \\ 0 & 0 & 0\end{array}$

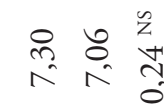

\begin{tabular}{ccc}
2 & \multirow{2}{z}{} \\
$\alpha$ & 0 & 0 \\
$\hat{\sigma}$ & 0 & 0 \\
0 & 0
\end{tabular}



$\simeq \begin{gathered}x \\ 1 \\ \text { 닌 }\end{gathered}$

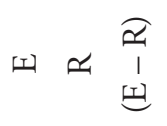

I $\simeq \begin{gathered}a \\ 1 \\ \text { 데 }\end{gathered}$

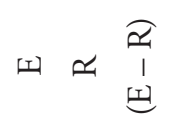

푀 $\simeq \begin{array}{r}\widehat{x} \\ 1 \\ \text { प1 }\end{array}$

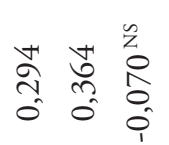

$-\quad 0$

1
0
1
0

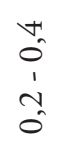

+1
0
1
0
0

0
0
0
1
$\vdots$
0

0
0
0
0
1
1
0
0

-1
0
0
0
1
0
0

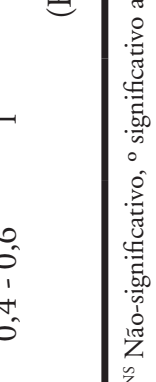


$(\mathrm{P}<0,05) \mathrm{da} \mathrm{CE}_{\mathrm{es}}$ apenas na camada de 0 a $0,2 \mathrm{~m}$, o qual foi três vezes menor que aquele observado com o efluente.

\section{DISCUSSÃO}

A utilização de efluentes ricos em nutrientes na irrigação de cultivos freqüentemente proporciona maiores produtividades em relação à irrigação com água doce (Sheikh et al, 1987; Chakrabarti, 1995). No presente estudo, o uso do efluente da carcinicultura na irrigação proporcionou um aumento significativo da produção de grãos de arroz quando a dose de N-P-K aplicada foi $25 \%$ menor que a dose recomendada. Esse efeito provavelmente ocorreu porque os nutrientes contidos no efluente, principalmente o nitrogênio, contribuíram para suprir os requerimentos nutricionais da cultura. Miranda et al (2005) estimaram que o efluente da carcinicultura de baixa salinidade, caso fosse utilizado na irrigação, poderia suprir até $30 \%$ das necessidades de nitrogênio da cultura do arroz.

Embora no presente estudo os níveis de nitrogênio e fósforo do efluente tenham sido superiores aos da água do Rio, não foram observadas diferenças estatisticamente significativas em virtude da alta variação dos dados durante o período de coleta das amostras de água. No entanto, em outro estudo realizado na Bacia do Rio Jaguaribe, Figueiredo et al (2005) observaram níveis mais elevados de nitrato, amônia e fósforo no efluente da carcinicultura em relação à água do Rio, principalmente durante a despesca.

Considerando-se que a lâmina total de água aplicada ao longo do ciclo da cultura do arroz foi de $2.860 \mathrm{~mm}$, estima-se que os aportes de nitrogênio através da irrigação com o efluente e com a água do Rio seriam de $180,2 \mathrm{~kg} \mathrm{ha}^{-1}$ e $82,7 \mathrm{~kg} \mathrm{ha}^{-1}$, respectivamente. Ou seja, o uso do efluente na irrigação aportaria cerca de $97,5 \mathrm{~kg} \mathrm{ha}^{-1}$ a mais de nitrogênio para a cultura, em relação à água do Rio Jaguaribe. No caso do fósforo e do potássio, as diferenças nos aportes seriam bem menores (com o uso do efluente seriam aplicados cerca de 4,0 $\mathrm{kg} \mathrm{ha}^{-1}$ e 17,5 $\mathrm{kg} \mathrm{ha}^{-1}$ a mais de $\mathrm{P}$ e $\mathrm{K}^{+}$, respectivamente).

Em contraste com os resultados do presente estudo, Miranda et al (2007) não observaram diferenças significativas em termos de produção e qualidade de frutos de melão, quando utilizaram na irrigação o efluente da

Tabela 6 - Diferenças médias observadas em algumas características químicas do solo (tempo I - tempo 0), nas profundidades de 0 a 0,2; 0,2 a 0,4 e 0,4 a 0,6 m, utilizando o efluente da carcinicultura de águas interiores (E) e a água do Rio Jaguaribe (R) na irrigação do arroz

\begin{tabular}{|c|c|c|c|c|c|}
\hline \multirow{2}{*}{$\begin{array}{l}\text { Tipo de } \\
\text { água }\end{array}$} & \multirow[t]{2}{*}{ Variável } & \multirow[t]{2}{*}{ Unidade } & \multicolumn{3}{|c|}{ Profundidade (m) } \\
\hline & & & $0-0,2$ & $0,2-0,4$ & $0,4-0,6$ \\
\hline $\mathrm{R}$ & $\mathrm{pH}$ & & $0,30 *$ & 0,18 & $0,30^{\mathrm{NS}}$ \\
\hline $\mathrm{E}$ & & & $0,04^{\mathrm{NS}}$ & $0,32^{\mathrm{NS}}$ & $0,02 \mathrm{NS}$ \\
\hline $\mathrm{R}$ & $\mathrm{P}$ & $\mathrm{mg} \mathrm{dm} \mathrm{m}^{-3}$ & $3,65^{* *}$ & $1,79^{\mathrm{NS}}$ & $2,84 *$ \\
\hline $\mathrm{E}$ & & & $2,99 *$ & $2,02 * *$ & $2,52 * *$ \\
\hline $\mathrm{R}$ & $\mathrm{K}+$ & cmolc $\mathrm{dm}^{-3}$ & $0,46^{* *}$ & $0,34 * *$ & $0,29 *$ \\
\hline $\mathrm{E}$ & & & $0,40^{* *}$ & $0,24 * *$ & $0,24 * *$ \\
\hline $\mathrm{R}$ & $\mathrm{Ca}^{2+}$ & cmolc dm ${ }^{-3}$ & $-3,13^{* *}$ & $-1,66 \mathrm{NS}$ & $-1,54$ NS \\
\hline $\mathrm{E}$ & & & $-1,57$ NS & $-1,40$ NS & $-4,70^{N S}$ \\
\hline $\mathrm{R}$ & $\mathrm{Mg}^{2+}$ & 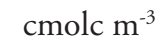 & $-0,66 * *$ & $-0,31 \mathrm{NS}$ & $-0,62^{N S}$ \\
\hline $\mathrm{E}$ & & & $-0,28^{\mathrm{NS}}$ & $-1,10^{\mathrm{NS}}$ & $-0,55^{\mathrm{NS}}$ \\
\hline $\mathrm{R}$ & $\mathrm{Na}^{+}$ & cmolc dm $\mathrm{dm}^{-3}$ & $1,42 *$ & $1,35^{* *}$ & $1,79^{* *}$ \\
\hline $\mathrm{E}$ & & & $1,82 * *$ & $1,55^{* *}$ & $1,35^{* *}$ \\
\hline $\mathrm{R}$ & $\mathrm{MO}$ & $\mathrm{g} \mathrm{dm}^{-3}$ & $0,60 \mathrm{NS}$ & $-0,40 \mathrm{NS}$ & $0,20^{\mathrm{NS}}$ \\
\hline $\mathrm{E}$ & & & $1,00 \mathrm{NS}$ & $-0,60 \mathrm{NS}$ & $-1,00 \mathrm{NS}$ \\
\hline $\mathrm{R}$ & $\mathrm{CE}_{\mathrm{es}}$ & $\mathrm{d} S \mathrm{~m}^{-1}$ & $0,24^{*}$ & $0,18^{\mathrm{NS}}$ & $0,14^{\mathrm{NS}}$ \\
\hline $\mathrm{E}$ & & & $0,82 * *$ & $0,74^{\mathrm{NS}}$ & $0,32^{* *}$ \\
\hline $\mathrm{R}$ & PST & $\%$ & $11,04^{* *}$ & $8,98^{* *}$ & $12,07^{*}$ \\
\hline $\mathrm{E}$ & & & $12,78^{* *}$ & 10,36 ** & $11,74 * *$ \\
\hline
\end{tabular}

Ns Não-significativo, * significativo a $5 \%$ de probabilidade e ${ }^{* *}$ Significativo a $1 \%$ de probabilidade. Obs.: Os dados constantes da Tabela 6 referem-se aos tratamentos E100 e R100.

carcinicultura e a água do Rio Jaguaribe, mesmo aplicando-se $75 \%$ da dose de $\mathrm{N}$ recomendada para a cultura. No entanto, a lâmina de irrigação aplicada durante o ciclo do melão (252 mm) foi bastante inferior àquela aplicada no presente estudo $(2.860 \mathrm{~mm})$. Consequentemente, as quantidades de nutrientes aportadas através da água de irrigação foram também bastante inferiores.

Com relação à salinidade do solo, o uso do efluente da carcinicultura na irrigação do arroz apresentou resultados menos satisfatórios que a água do Rio Jaguaribe. Embora ambos os tipos de água tenham causado aumentos significativos nos níveis de $\mathrm{Na}^{+}, \mathrm{CE}_{\mathrm{es}}$ e PST do solo, esses aumentos foram mais expressivos com o uso do efluente, principalmente na camada de 0 a $0,40 \mathrm{~m}$ de profundidade. Tal efeito pode ser atribuído à maior concentração salina do efluente (expressa pelo nível mais elevado de $\mathrm{CE}_{\mathrm{a}}$ ), em relação à água do Rio Jaguaribe.

\section{CONCLUSÕES}

Nas condições em que foi realizado o estudo concluiu-se que:

- O efluente da carcinicultura de águas interiores pode ser utilizado na irrigação de cultivos como o arroz, proporcionando produçóes semelhantes às obtidas com a água de rio, ou até superiores, quando a dose de N-P-K aplicada na adubação for menor que a recomendada.

- O uso do efluente da carcinicultura de águas interiores na irrigação é viável agronomicamente e pode contribuir para o aumento da eficiência hídrica nas fazendas de camarão. No entanto, tal uso deve ser acompanhado da drenagem do solo e do monitoramento periódico da condutividade elétrica $\left(\mathrm{CE}_{\mathrm{es}}\right)$ e da porcentagem de sódio trocável (PST) do solo, a fim de detectar e prevenir sua salinização. 


\section{AGRADECIMENTOS}

Os autores agradecem à FINEP e ao $\mathrm{CNPq}$ pelo financiamento para a realização da pesquisa e aos proprietários e funcionários da Fazenda Poço de Onça, pela colaboração na realização do experimento.

\section{REFERÊNCIAS}

AYERS, R.S., WESTCOT, D.W. A qualidade da água na agricultura. Campina Grande. UFPb, (FAO. Irrigação e Drenagem, 29). 218 p., 1999.

BOYD C.E. Guidelines for aquaculture effluent management at the farm-level. Aquaculture, v. 226, p. 101-12, 2003

CHAKRABARTI, C. Residual effects of long-term land application of domestic wastewater. Environment International, v. 21, p. 333-39, 1995.

DIERBERG, F.E.; KIATTISIMKUL, W. Issues, impacts, and implications of shrimp aquaculture in Thailand. Environmental Management, v. 20, p. 649-66, 1996.

FIGUEIREDO, M.C.B. et al. Impactos ambientais do lançamento de efluentes da carcinicultura em águas interiores. Engenharia Sanitária e Ambiental, v. 10, n. 2, p. 167-74, 2005.

MCINTOSH, D. et al. Toward integrating olive production with inland shrimp farming. World Aquaculture, v. 34, p. 16-20, 2003.
MIRANDA, F.R. et al. Irrigação com efluentes da carcinicultura em águas interiores. In: WORKSHOP USO E REÚSO DE ÁGUAS DE QUALIDADE INFERIOR: REALIDADES E PERSPECTIVAS, Anais ... Campina Grande: UFCG, CD-ROM, 2005.

MIRANDA, F.R. et al. Reuiso de efluentes da carcinicultura de águas interiores na irrigação da cultura do melāo. In: III CONGRESO INTERNACIONAL DE RIEGO Y DRENAJE, Anais ... Varadero, Cuba:IPID, CD-ROM, 2007.

PAEZ-OSUNA, F., GUERRERO-GALVAN, S.R., RUIZ-FERNANDEZ, A.C. The environmental impact of shrimp aquaculture and the coastal pollution in Mexico. Marine Pollution Boletim, v. 36, p. 165-75. 1998.

PIZARRO, F. Drenaje Agricola y Recuperación de Suelos Salinos. Madrid. Ed. Agrícola Española, 521 p., 1978.

RAIJ, B. et al. Recomendaçôes de adubação e calagem para o Estado de São Paulo. 2 ed. Campinas. Instituto Agronômico/Fundação IAC, 285p., 1997.

SHEIKH, B., JAQUES, R.S., CORT, R.P. Reuse of tertiary municipal wastewater effluent for irrigation of raw-eaten food crops: a five year study. Desalination, v. 67, p. 245-54, 1987.

SILVA, F.C. Manual de analises quimicas de solo, plantas e fertilizantes. Brasília. Embrapa, 370 p., 1999 .
Endereço para correspondência:

Fábio Rodrigues de Miranda Embrapa Agroindústria Tropical

Rua Dra. Sara Mesquita, 2.570 605 I I-I IO - Fortaleza - CE Brasil

Tel.: (85) 3299-19/2

Email: fabio@cnpat.embrapa.br 